\title{
PENGEMBANGAN STRATEGI LABORATORIUM UJI PT XYZ
}

\author{
STRATEGY DEVELOPMENT FOR TEST LABORATORY OF PT XYZ
}

\author{
Adi Mulyadi ${ }^{* 1}$, Sahara ${ }^{* *}$, dan Kirbrandoko $\left.{ }^{* * *}\right)$ \\ *) Sekolah Bisnis, IPB University \\ Jl. Raya Pajajaran, Bogor 16151 \\ **) Departemen Ilmu Ekonomi, Fakultas Ekonomi dan Manajemen, IPB University \\ Jl. Agatis, Kampus IPB Darmaga, Bogor 16680 \\ ${ }^{* * *}$ Universitas Ibn Khaldun Bogor \\ Jl. Sholeh Iskandar, Kota Bogor 16162
}

\begin{abstract}
Increasing population, human welfare, awareness of product safety in order to meet the regulation requires a reliable test laboratory. Competition among service-laboratory made PT XYZ as a test laboratory faces competition with other laboratories. This research aimed to analyze the strategy development of PT XYZ in order to 1) analyze the company's internal and external factors in the service laboratory industry, 2) determine company alternative strategies, 3) recommend the best strategy from these alternatives. The study used IFAS (Internal Factor Analysis Summary), and EFAS (External Factor Analysis Summary), IE (Internal External), and SWOT (Strengths Weakness Opportunities Threats) matrix. The internal analysis found five factors respectively, for strengths and weaknesses, while the external factor found five factors, respectively for opportunities and threats. The scores from IFAS and EFAS matrix analysis were of 2,785 and 2,583, respectively. These scores represented the company's position in the IE matrix, which was on cell $V$. Thus, the related strategy was hold and maintain. The formulated alternative strategies were market penetration, product development, and service differentiation.
\end{abstract}

Keywords: alternative strategies, EFAS, IE, IFAS, service laboratory, SWOT

\begin{abstract}
Abstrak: Populasi yang meningkat, kesejahteraan, kesadaran akan produk yang aman, dan untuk memenuhi kebutuhan regulasi diperlukan suatu laboratorium uji yang handal. Persaingan di bidang laboratorium layanan menjadikan PT XYZ sebagai laboratorium penguji harus mampu bersaing dengan laboratorium lain. Penelitian ini bertujuan 1) menganalisis faktor internal dan eksternal perusahaan dalam industri laboratorium jasa, 2) menentukan strategi alternatif yang dapat dilakukan oleh perusahaan, 3) merekomendasikan strategi terbaik dari berbagai alternatif. Metode yang digunakan pada penelitian ini adalah IFAS (Internal Factor Analysis Summary) dan EFAS (External Factor Analysis Summary), IE (Internal External), dan matriks SWOT (Strengths Weakness Opportunity Threaths). Analisis internal menunjukkan 5 faktor kekuatan dan 5 faktor kelemahan, sedangkan faktor eksternal menunjukkan 5 faktor peluang dan 5 faktor ancaman. Analisis matriks IFAS dan EFAS menunjukkan skor 2,785 dan 2,583. Skor ini menunjukkan bahwa posisi perusahaan pada matriks IE berada di sel V. Strategi yang tepat dalam kuadran ini adalah menjaga dan mempertahankan. Strategi alternatif yang dirumuskan untuk perusahaan adalah penetrasi pasar, pengembangan produk dan strategi diferensiasi layanan.
\end{abstract}

Kata kunci: alternatif strategi, IFAS, IE, EFAS, laboratorium jasa, SWOT

\footnotetext{
${ }^{1}$ Corresponding author:

Email: adimulyadi0803@gmail.com
} 


\section{PENDAHULUAN}

Pertambahan jumlah penduduk, peningkatan kesejahteraan, dan kesadaran akan mutu pangan serta regulasi yang ada, memberikan peluang usaha bagi industri jasa laboratorium pengujian pangan di Indonesia. Banyaknya laboratorium jasa analisa yang sejenis menjadikan persaingan yang semakin dinamis di bidang laboratorium pengujian dengan jaminan mutu dan validasi yang tinggi. Persaingan terjadi bukan saja di dalam negeri dan internasional akan tetapi saat ini menjadi tantangan tersendiri terutama area persaingan bebas, ASEAN Free Trade Area, AFTA (Munandar, 2011). Laboratorium lokal yang dikelola pemerintah maupun swasta nasional harus tetap terjamin dan tetap menjaga mutu barang maupun jasa yang dihasilkan sesuai hasil pengujian laboratorium.

Faktor yang mendorong perubahan dalam industri laboratorium diantaranya adalah teknologi dan globalisasi, kebijakan politik, pemerintahan dan perundang-undangan yang juga dapat menjadi peluang dan ancaman bagi perusahaan kecil maupun besar. Data dari Komite Akreditasi Nasional (KAN) tahun 2018 menunjukkan laboratorium uji yang terdaftar dan mendapatkan sertifikat akreditasi sebanyak 1.162 sehingga persaingan antar laboratorium untuk memberikan pelayanan terbaiknya sangat kompetitif.

PT XYZ merupakan perusahaan jasa laboratorium uji di bidang pangan yang telah terakreditasi oleh KAN. Dalam upaya memenuhi kebutuhan para pelanggan, PT XYZ terus meningkatkan kompetensinya dengan memperluas ruang lingkup akreditasi di bidang keamanan pangan. Layanan yang dilakukan salah satunya adalah produk yang akan mendapatkan ijin edar harus melalui uji laboratorium yang independen sebelum didaftarkan ke Badan Pengawasan Obat dan Makanan Republik Indonesia (BPOM RI) berupa nomor MD untuk produk yang dijual di dalam negeri dan nomor ML untuk produk yang akan dijual di luar negeri ataupun produk luar yang akan dijual di dalam negeri. Sebagai regulator, BPOMN memiliki kewenangan dalam memonitoring dan mengeluarkan sertifikat pengujian melalui Pusat Pengujian Pengawasan Obat dan Makanan Nasional (PPPOMN).

Pertumbuhan pengujian produk yang telah dilakukan oleh PTXYZ dibandingkan dengan sertifikat (pengujian) produk yang dikeluarkan oleh PPPOMN, PT XYZ baru mengujikan produk sekitar $20-30 \%$ dari pengujian produk yang dikeluarkan oleh PPPOMN pada tahun 2015-2016 sehingga masih ada peluang yang dapat dikembangkan oleh PT XYZ (Gambar 1). Pengujian sampel atau produk-produk tersebut adalah beberapa produk pangan, sedikit produk farmasi, kosmetik dan produk kecantikan, serta produk kesehatan lainnya.

PT XYZ harus siap mendukung kebijakan pemerintah dan tuntutan masyarakat umum dalam hal pengujian yang bermutu yang mampu menghasilkan laporan hasil uji. Hasil laporan ini merupakan salah satu syarat dari sertifikat keamanan produk yang dikeluarkan oleh regulator. Melalui perencanaan strategi yang baik, PT XYZ berkeyakinan akan memberikan kepercayaan kepada pelanggan terutama industri pangan, obat, kosmetik serta produk konsumtif nasional dan internasional untuk mengujikan produknya. Oleh karena itu, perumusan upaya antisipatif dan strategi pengembangan oleh perusahaan yang dilakukan agar dapat bersaing dan tetap berkembang serta menjadi pemain utama pada industri jasa laboratorium pangan, sangatlah diperlukan.

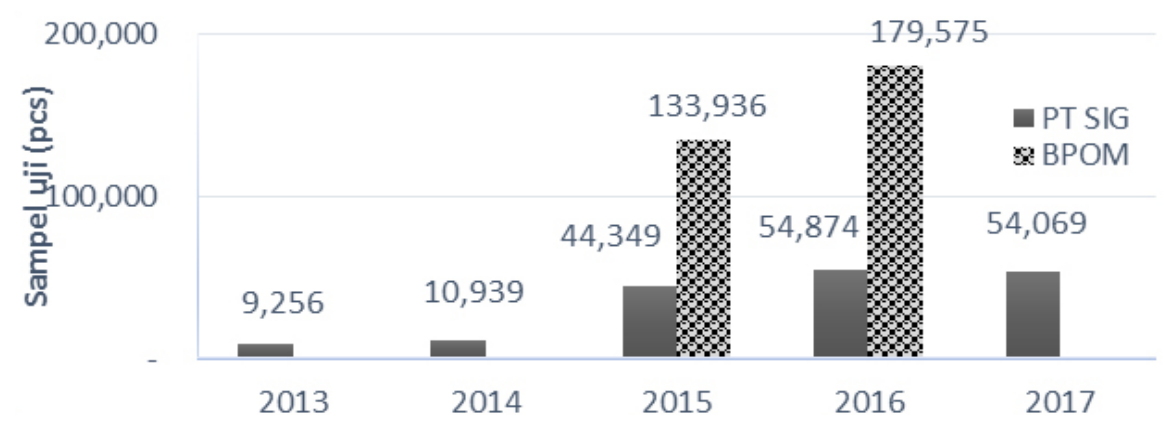

Gambar 1. Jumlah sampel uji PT XYZ dan PPPOMN tahun 2013-2017 
Strategi pengembangan harus didasarkan pada bagaimana perusahaan dapat bersaing secara unggul di pasar (Pearce, 2014). Purwani (2019) menyebutkan pada perumusan strategi, perusahaan harus mengetahui kekuatan, kelemahan, peluang dan ancaman. Perusahaan yang tidak melakukan analisis terhadap kekuatan, kelemahan, peluang dan ancaman maka perusahaan tersebut tidak akan produktif. Dalam menghadapi tantangan tersebut, Nurhasanah (2013) menyebutkan bahwa dalam strategi pengembangan laboratorium, organisasi harus mempunyai strategi yang selalu dievaluasi dan dirumuskan ulang sehingga dapat bersaing dengan yang lainnya serta pentingnya strategi penetrasi pasar, pengembangan pasar, dan pengembangan produk.

Perusahaan dengan pernyataan visi yang terformalisasi mempunyai rata-rata return on share holder equity dua kali lebih tinggi dibandingkan dengan perusahaan yang mempunyai pernyataan visi yang tidak terformalisasi dan ada hubungan positif antara pernyataan misi dengan kinerja organisasi (Hutabarat, 2006). Menurut David (2013), sebuah organisasi mencapai tujuannya yaitu dengan mengintegrasikan manajemen, pemasaran, produksi, penelitian dan pengembangan serta sistem informasi untuk mencapai keberhasilan operasional. Penelitian dari Suprapto et al. (2017) yang bergerak di bidang pengujian mineral bertujuan mengidentifikasi kinerja, apakah visi dan misi sesuai dengan kompetensinya, serta penetapan program sebagai acuan perencanaan SBU mineral berikutnya dan merekomendasikan strategi bisnis yang tepat untuk diterapkan dalam menghadapi tekanan persaingan serta menyusun tujuan/sasaran dan program SBU Mineral. Abdurrahim et al. (2014) pada penelitian strategi manajemen di bidang usaha laboratorium menggunakan analisis internal dan eksternal dengan alternatif strategi menggunakan analisis SWOT. Putra et al. (2017) dalam model perbaikan bisnis pada laboratorium bahan beton menggunakan model bisnis canvas. Hal yang sama dilakukan oleh Kamila et al. (2017) dalam analisa pengembangan bisnis madu melalui pendekatan model bisnis canvas yang dipetakan dalam sembilan elemen. Elemen prioritas kemudian dilakukan dengan analisis SWOT untuk mengidentifikasi kondisi internal dan eksternal. Nugroho (2017) pada penelitian strategi bisnis dalam jasa lainnya, perusahaan difokuskan dengan memberikan pelayanan yang optimal dengan fasilitas pendukung berupa terintegrasinya sistem teknologi informasi dalam kegiatan operasional. Hasnam et al. (2017) melakukan penelitian strategi pengembangan pada perusahaan jasa yang lain dalam pengelolaan sampah dengan megidentifikasi faktor internal dan eksternal serta pengaruhnya dengan analisis SWOT. Suryani et al. (2014) dalam pengembangan strategi lembaga penelitian untuk mencapai kinerja dengan menggunakan strategy map, memiliki hubungan perspektif sasaran strategis yang berbeda-beda diantara peta strategi.

Sebagai perusahaan jasa maka laboratorium uji PT XYZ harusmemperlihatkanmutu, baik produkyangdihasilkan maupun layanan yang diberikan dengan meningkatkan produktivitas, layanan kepuasan pelanggan, dan inovasi dalam proses bisnis yang mengarah kepada peningkatan pendapatan. Menurut Widyastutik dan Reni (2014), kebijakan yang menyangkut mutu dan standar yang meningkatkan daya saing salah satunya dengan uji mutu melalui laboratorium yang handal. Dewi et al. (2018) dan Azzuhro (2015) merumuskan perencanaan strategi pada bisnis jasa salon dan spa yang ceruk pasarnya unik dengan persaingan pada tingkat kualitas yang tinggi dan harga yang rendah menyebutkan bahwa perusahaan perlu bersaing pada tingkat kualitas yang tinggi dengan harga yang bersaing sedikit lebih rendah dari pesaing serta perlunya strategi penetrasi pasar. Penelitian jasa salon dan spa ini mirip dengan industri jasa layanan laboratorium yang dalam operasionalnya harus menjamin bahwa jasa yang dihasilkan bermutu dan orang yang melakukannya kompeten. Rachman et al. (2017) dalam strategi loyalitas merek dan kepuasan pelanggan, menganalisa strateginya menggunakan kerangka PESTEL (Politik, Ekonomi, Sosial Budaya, Teknologi, Lingkungan) dan analisis Porter's five forces. Singh et al. (2018) menyatakan kualitas layanan dan kepuasan pelanggan adalah masalah yang tidak terpisahkan yang akan mengarah pada layanan yang lebih tinggi pengakuan dan meningkatkan kinerja organisasi pada laboratoium diagnostik kesehatan, seperti penelitian yang dilakukan oleh Kaoje et al. (2017) untuk menilai kualitas layanan maka harus memiliki pelatihan manajemen kualitas laboratorium.

Penelitian oleh Wieklati (1998) dan Munandar (2011) bahwa prioritas strategi untuk meningkatkan efektivitas pemasaran adalah melakukan promosi dan edukasi dengan menginformasikan kualitas jasa, cakupan produk ruang lingkup dan parameternya yang sudah terakreditasi kepada perusahaan pangan yang membutuhkan jasa laboratorium pengujian. Selain itu, dengan melakukan kampanye budaya keamanan pangan kepada publik dengan mengangkat isu-isu keamanan 
pangan sebagai bentuk promosi dan edukasi untuk menaikkan citra perusahaan. Michael Porter dalam Wheelen dan Hunger (2012) menawarkan dua strategi bersaing generik untuk mengungguli perusahaan lain dalam industri tertentu. Menurut Dila et al. (2014) bahwa strategi jangka panjang sebaiknya diturunkan dari usaha perusahaan untuk mencari keunggulan kompetitif berdasarkan biaya rendah dan diferensiasi.

Beberapa penelitian perencanaan strategik sebelumnya yang terkait dengan perusahaan jasa laboratorium pengujian yaitu melalui pendekatan analisis kinerja dengan metode Balanced Scorecard (BSC) di PT Sucofindo (Suprapto, 2017) dan strategi pada pemasaran oleh Munandar (2011) di PT MBrio. Penelitian yang dilakukan di laboratorium uji PT XYZ merupakan penelitian awal, maka tujuan penelitian ini adalah menganalisa pengembangan strategi yang telah dilakukan. Dengan melakukan analisis mendalam terhadap faktor internal dan eksternal perusahaan diharapkan dapat mendorong keunggulan yang berkelanjutan dengan memanfaatkan sumber daya yang dimiliki.

Analisapengembangan strategiyang dilakukan terhadap perusahaan yang diteliti menggunakan teori Wheelen dan Hunger (2012) yang meliputi analisis visi, misi, serta analisis lingkungan internal dan eksternal untuk merumuskan faktor-faktor strategis (IFAS dan EFAS). Alat analisa yang digunakan adalah matrik internaleksternal (IE) dan matrik SWOT/TOWS dengan batasan sampai proses perumusan strategi perencanaan jangka panjang, yaitu 3 sampai 5 tahun.

Analisis internal dilakukan dengan rantai nilai dan VRIO sehingga mengetahui lebih dalam tentang proses dan kinerja kekuatan dan kelemahan yang telah dilakukan. Untuk analisis eksternal dilakukan dengan analisis PESTEL yang lebih luas cakupannya dan lima kekuatan Porter's untuk mengetahui tingkat persaingan bisnis jasa laboratorium uji, baik ancaman dan peluang. Berdasarkan latar belakang dan permasalahan yang ada, tujuan dari penelitian ini adalah menganalisis faktor lingkungan internal dan eksternal PT XYZ; menganalisis alternatif strategi yang tepat untuk PT XYZ; dan menyusun formulasi strategi PT XYZ tahun 2019-2023.

\section{METODE PENELITIAN}

Penelitian dilakukan di PT XYZ yang terletak di Taman Yasmin, Bogor. Penelitian, pengolahan data, dan penulisan dilaksanakan selama lima bulan pada akhir Juni sampai November 2018. Metode penelitian yang digunakan adalah metode kualitatif deskriftif dengan pendekatan studi kasus pada objek penelitian. Pendekatan kualitatif deskriptif digunakan untuk mendapatkan gambaran informasi, penjelasan serta kondisi yang berkaitan dengan objek penelitian secara faktual, akurat dan sistematis mencakup visi, misi, dan kinerja.

Data yang digunakan dalam penelitian ini adalah data primer dan data sekunder yang bersifat kualitatif dan kuantitatif. Data primer didapatkan melalui pengamatan langsung, sementara data sekunder diperoleh dari laporan tahunan keuangan, data hasil survei kepuasan pelanggan, kompetitor, literatur, dan internet.

Teknik yang digunakan untuk mendapatkan informasi tersebut antara lain dengan observasi, dept interview dengan pakar manajemen laboratorium, direktur utama, direktur operasional, dan para manajer dari objek penelitian tersebut. Teknik pengambilan data melalui pengambilan sampel ditentukan secara sengaja (purposive sampling dengan judgement sampling) terdiri dari responden internal dan eksternal klien.

Berdasarkan latar belakang, rumusan permasalahan dan tujuan penelitian maka kerangka pemikiran yang dijadikan acuan, yaitu adanya persaingan di industri jasa laboratorium sehingga layanan pengujian belum terpenuhi secara maksimal. Oleh karena itu, diperlukan alternatif strategi yang dijalankan dan penentuan perencanaan strategi yang akan datang. Kerangka pemikiran penelitian dapat dilihat pada Gambar 2.

Penelitian dibagi menjadi beberapa tahapan sesuai dengan tujuan penelitian. Tahapan pertama adalah mendeskripsikan visi dan misi serta mengidentifikasi kompetensi inti PT XYZ, dilanjutkan dengan menganalisis lingkungan internal untuk mengkaji kinerja serta faktor kekuatan dan kelemahan PT XYZ. Selanjutnya, menganalisis lingkungan eksternal makro (Political, Economic, Social dan Technology/PESTEL) serta menganalisis lingkungan eksternal mikro (Five Forces Porter) untuk mengetahui tingkat persaingan 
bisnis jasa laboratorium uji. Alat analisis yang digunakan adalah IFAS dan EFAS, IE, dan SWOT. Hasil dari analisis eksternal dan internal dijadikan bahan untuk analisis SWOT untuk merumuskan strategi PT XYZ yang dibutuhkan. Perumusan dilakukan dengan cara menggabungkan strategi dari faktor eksternal dan internal organisasi yang menjadi kunci dari isu strategi bisnis yaitu cara penggabungan SO, ST, WO, WT yang perumusannya dibatasi berdasarkan rekomendasi strategi pengembangan dari kombinasi hasil analisis IE. Formulasi strategi dianalisis menggunakan strategi bersaing Generik Porter. Tahapan berikutnya adalah menyusun tujuan/sasaran dan program PT XYZ lima tahun ke depan.

\section{HASIL}

\section{Gambaran Umum Perusahaan}

PT XYZ Bogor merupakan salah satu perusahaan yang pada awalnya mengkhususkan diri sebagai laboratorium jasa deteksi produk hasil rekayasa genetika, Genetically Modified Organism (GMO), atau transgenik serta jasa identifikasi bakteri. Untuk menjamin mutu, PT XYZ mengikuti berbagai uji profisiensi biotek serta berbagai uji profisensi yang diadakan di dalam negeri sesuai dengan ruang lingkup pengujian. PT XYZ terus meningkatkan kompetensinya dengan penambahan ruang lingkup. Selain uji analisis GMO (biotek), terdapat juga uji mikrobiologi, uji kimia seperti uji proksimat, kandungan gizi, uji keamanan pangan, dan uji untuk pemenuhan regulasi lainnya.

PT XYZ selain memiliki Laboratorium Mikrobiologi dan Bioteknologi, Laboratorium Analitik Instrumen, Laboratorium Analitik Proksimat, juga memiliki Laboratorium Penelitian dan Pengembangan (Research and Development atau R\&D) guna mendukung dalam pengembangan dan penambahan ruang lingkup pengujian. Diharapkan PT XYZ akan terus mampu mengembangkan metode-metode uji mutakhir yang dibutuhkan oleh pelanggan, seperti pengawasan mutu produk, pengembangan produk, dan registrasi produk yang akan diedarkan oleh perusahaan atau pelanggan yang membutuhkan jasa uji untuk mengetahui kandungan nutrisi, zat yang berbahaya dan kelayakan suatu produk (keamanan pangan/produk).

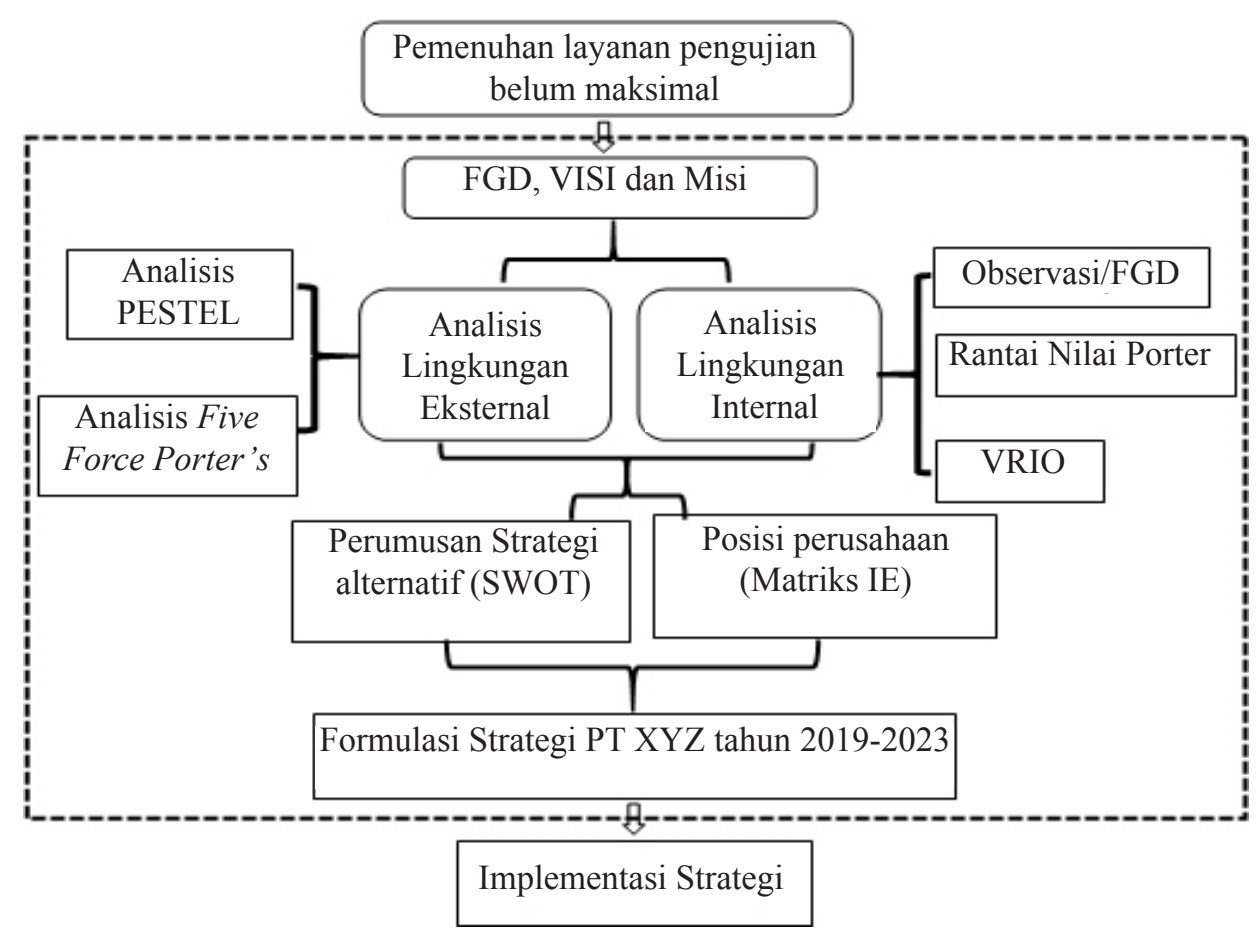

Gambar 2. Kerangka Pemikiran 


\section{Faktor Lingkungan Internal dan Eksternal PT XYZ}

Analisis faktor lingkungan internal dan eksternal yang pertama dilakukan adalah analisis menentukan visi dan misi objektif dengan mendeskripsikan visi dan misi serta tujuan PT XYZ dalam rangka menganalisis permasalahan dan faktor-faktor dominan yang menentukan dalam formulasi pengembangan strategi yang akan dibuat. Visi dari PT XYZ adalah "PT XYZ sebagai one stop food laboratory yang kredibel sehingga dapat mendarmabaktikan talenta yang bermanfaat bagi kemajuan dan kesejahteraan negeri tercinta indonesia dan laboratorium yang memiliki kompetensi handal dalam menghasilkan data pengujian yang akurat dan presisi tinggi".

Untuk mencapai suatu visi yang telah ditetapkan maka perusahaan perlu menetapkan suatu misi. Misi dari perusahaan PT XYZ itu sendiri adalah: berorientasi pada pemenuhan kepuasan pelanggan (customer satisfaction), menerapkan dan mengembangkan Good Profesional Practice serta menerapkan prinsip kerja "benar sejak awal" sesuai sistem manajemen mutu ISO/IEC 17025:2005 dan meningkatkan efektivitas sistem manajemen mutu secara berkelanjutan.

Berdasarkan analisis dan hasil diskusi kelompok terarah dengan narasumber dari PT XYZ sendiri dan dari eksternal, maka visi dan misi yang dinyatakan dalam kebijakan mutunya dapat dinilai cukup baik karena menggunakan kalimat jelas, singkat, dan mampu memberikan gambaran kompetensi khusus dari PT XYZ. Pernyataan visi perlu dievalusi agar sesuai dengan rencana jangka panjang dari perusahaan, masa kini dan masa yang akan datang. Pernyataan visi harus dipertajam dan luas cakupannya. Berdasarkan waktu dan situasi eksternal maka visi tersebut sudah saatnya dievaluasi dan diperbaiki dalam waktu dekat. Usulan dari hasil diskusi kelompok yang terarah maka visi PT XYZ menjadi "One stop food laboratory" yang kredibel, terkemuka di Indonesia dan dunia“. Adapun sistem manajemen mutu ISO/IEC 17025:2005 yang dinyatakan dalam misi masih tertulis untuk seri tahun 2005. Untuk tahap berikutnya harus diganti menyesuaikan revisi dari ISO versi 2005 menjadi versi 2017 sehingga lebih lengkapnya tercatat ISO 17025:2017.
Analisis selanjutnya adalah analisis lingkungan internal, yaitu analisis rantai nilai dan VRIO (Value, Rarity, Imitability, Organization). Berdasarkan hasil analisis rantai nilai dan VRIO didapatkan 10 faktor strategi yang menjadi kekuatan dan kelemahan (Faktor Internal) yang paling berpengaruh terhadap PT XYZ (Tabel 1).

Analisis persaingan industri dilakukan berdasarkan pada konsep Competitive Strategy Porter dalam Manajemen Pemasaran (Kotler, 2009) yang menganalisis persaingan bisnis berdasarkan lima variabel utama yang disebut lima kekuatan bersaing. Kelima kekuatan bersaing itu antara lain tingkat persaingan dalam industri, ancaman pendatang baru, ancaman produk subtitusi, kekuatan tawar menawar pemasok, dan kekuatan tawar menawar pembeli. Berdasarkan hasil analisis lingkungan eksternal mengunakan PESTEL dan lima kekuatan Porters didapatkan data faktor peluang dan ancaman yang dapat mempengaruhi aktivitas perusahaan dan tindakan bersaing perusahaan. Hasil analisis eksternal ini menghasilkan 10 faktor strategis berupa peluang dan ancaman (Faktor Eksternal) yang paling berpengaruh terhadap PT XYZ (Tabel 2).

Penilaian faktor internal dan eksternal dilakukan dengan memberikan bobot dan peringkat. Bobot menunjukkan tingkat kepentingan faktor-faktor strategis dalam menunjang keberhasilan PT XYZ dalam menjalankan usahanya. Peringkat menunjukkan kemampuan PT XYZ dalam mengakomodasi faktor tersebut. Hasil evaluasi terhadap faktor strategis dinyatakan dalam matrik / rekapitulasi faktor internal dan eksternal (IFAS dan EFAS).

Hasil analisis, pembobotan, dan rating faktor internal disajikan dalam tabel IFAS. Penilaian kekuatan dan kelemahan digunakan nilai 1 sampai 4. Nilai 1 (kelemahan utama), 2 (kelemahan kecil), 3 (kekuatan kecil), dan 4 (kekuatan utama). Berdasarkan hasil olahan matrik IFAS maka diperoleh nilai diatas 2,5 yaitu 2,785 yang berarti perusahaan dapat memanfaatkan kekuatan dan mampu menghadapi kelemahan serta perusahaan telah memiliki strategi yang baik untuk mengurangi kelemahan internal yang ada. 
Tabel 1. Rekapitulasi Internal Factor Analysis Summary (IFAS)

\begin{tabular}{|c|c|c|c|c|}
\hline \multicolumn{5}{|l|}{ Faktor Strategis Internal } \\
\hline (IFAS) & Bobot & Rating & Skor & Keterangan \\
\hline \multicolumn{5}{|l|}{ Kekuatan } \\
\hline Dukungan peralatan analisa & 0,089 & 4 & 0,356 & Alat yang mendukung validitas uji \\
\hline Kontrak pengujian yang mudah & 0,080 & 3 & 0,240 & $\begin{array}{l}\text { didukung oleh sistem data base dan sistem } \\
\text { informasi terintegrasi yang dikembangkan } \\
\text { sendiri }\end{array}$ \\
\hline kecepatan informasi kepada pelanggan & 0,083 & 3 & 0,249 & waktu pengujian yang cepat \\
\hline $\begin{array}{l}\text { Insentif untuk karyawan dan kepuasan kerja } \\
\text { karyawan }\end{array}$ & 0,109 & 4 & 0,436 & $\begin{array}{l}\text { sesuai total penjualan/layanan pengujian } \\
\text { setiap bulan }\end{array}$ \\
\hline $\begin{array}{l}\text { Aktivitas penelitian dan pengembangan pengu- } \\
\text { jian }\end{array}$ & 0,111 & 4 & 0,444 & $\begin{array}{l}\text { informasi dari bagian pemasaran sangat } \\
\text { penting }\end{array}$ \\
\hline \multicolumn{5}{|l|}{ Kelemahan } \\
\hline Kecepatan dan lama pengujian & 0,112 & 2 & 0,224 & $\begin{array}{l}\text { direspon dengan baik dan berupaya } \\
\text { meningkatkan kinerja }\end{array}$ \\
\hline $\begin{array}{l}\text { Kecermatan dalam preparasi sampel uji dan } \\
\text { pembuatan data uji }\end{array}$ & 0,124 & 2 & 0,248 & merespon dengan sistem data base \\
\hline $\begin{array}{l}\text { Mutu layanan, pelatihan dan pendidikan untuk } \\
\text { pelanggan dalam penanganan komplain }\end{array}$ & 0,092 & 2 & 0,184 & perlu ditingkatkan \\
\hline Rasio jumlah pelatihan sesuai dengan kompetensi & 0,089 & 2 & 0,178 & $\begin{array}{l}\text { perlu ditingkatkan, ruang lingkup pekerjaan } \\
\text { karyawan / pengembangan personal }\end{array}$ \\
\hline \multirow[t]{2}{*}{ Jaminan mutu metode pengujian yang sulit } & 0,113 & 2 & 0,226 & perlu pelatihan \\
\hline & 1,00 & & 2,785 & \\
\hline
\end{tabular}

\section{Tabel 2. Rekapitulasi External Factor Analysis Summary ( EFAS)}

\begin{tabular}{|c|c|c|c|c|}
\hline \multicolumn{5}{|l|}{ Faktor Strategis Eksternal } \\
\hline (EFAS) & Bobot & Rating & Skor & Keterangan \\
\hline \multicolumn{5}{|l|}{ Peluang } \\
\hline $\begin{array}{l}\text { Pemberlakuan pengujian terhadap produk } \\
\text { (regulasi) }\end{array}$ & 0,113 & 3 & 0,339 & $\begin{array}{l}\text { Mengikuti trend produk yang dipasarkan dan } \\
\text { pengujian yang dilakukan }\end{array}$ \\
\hline $\begin{array}{l}\text { Asosiasi/Jejaring laboratorium pengujian yang } \\
\text { aktif }\end{array}$ & 0,086 & 3 & 0,258 & $\begin{array}{l}\text { Memberikan masukan dan kontribusi } \\
\text { pengujian yang masih sulit dikembangkan di } \\
\text { Indonesia }\end{array}$ \\
\hline $\begin{array}{l}\text { Edukasi masyarakat mengenai keamanan dan } \\
\text { ketahanan pangan }\end{array}$ & 0,093 & 3 & 0,279 & $\begin{array}{l}\text { Mengikuti seminar mengenai keamanan } \\
\text { pangan, Jumlah penduduk dan tingkat } \\
\text { pendidikan }\end{array}$ \\
\hline $\begin{array}{l}\text { Perusahaan pendukung / pemasok alat dan bahan } \\
\text { uji }\end{array}$ & 0,099 & 4 & 0,396 & $\begin{array}{l}\text { Pembelian alat disesuaikan dengan informasi } \\
\text { dari marketing/tren pengujian }\end{array}$ \\
\hline $\begin{array}{l}\text { Teknologi pengujian dan sistem informasi } \\
\text { pengujian }\end{array}$ & 0,091 & 3 & 0,273 & $\begin{array}{l}\text { Selalu merespon teknologi yang } \\
\text { memudahkan analisa }\end{array}$ \\
\hline \multicolumn{5}{|l|}{ Ancaman } \\
\hline $\begin{array}{l}\text { Produk pengujian (parameter) yang lengkap dari } \\
\text { pesaing }\end{array}$ & 0,117 & 2 & 0,234 & Memperkuat pengujian yang baru \\
\hline Harga uji jasa layanan & 0,119 & 2 & 0,238 & sangat kompetitif dalam harga (perang harga) \\
\hline Peningkatan kapasitas pengujian (lama waktu uji) & 0,117 & 2 & 0,234 & Kompetensi di setiap bagian \\
\hline Pencemaran limbah yang dihasilkan & 0,081 & 2 & 0,162 & $\begin{array}{l}\text { Mengikuti regulasi yang dikeluarkan oleh } \\
\text { dinas lingkungan daerah }\end{array}$ \\
\hline $\begin{array}{l}\text { Pengaruh kebijakan pemerintah terhadap } \\
\text { munculnya perusahaan baru }\end{array}$ & 0,085 & 2 & 0,170 & $\begin{array}{l}\text { Memperhatikan penambahan laboratorium } \\
\text { yang terakreditasi }\end{array}$ \\
\hline & 1,00 & & 2,583 & \\
\hline
\end{tabular}


Berdasarkan Tabel 1 terlihat bahwa faktor utama dari kekuatan adalah aktivitas penelitian dengan skor 0,444. Penelitian merupakan kegiatan yang sangat penting dan upaya yang telah dilakukan harus terus ditingkatkan sesuai dengan permintaan uji dari produk-produk yang baru dan sejalan dengan visi dan misi PT XYZ sebagai laboratorium pengujian yang lengkap guna memenuhi harapan pelanggan. PT XYZ selalu merencanakan penambahan parameter uji yang terdaftar dalam lingkup pengujian sehingga setiap kali masa surveilen atau reakreditasi dari Komite Akreditasi Nasional (KAN) secara konsisten menambah pengujian yang telah tervalidasi. Banyaknya pengujian yang terdaftar dalam ruang lingkup akan menambah kompetensi dan memenuhi harapan dari permintaan uji dari pelanggan, baik dari industri maupun regulasi serta lembaga yang berkaitan dengan keamanan suatu produk. Sementara faktor utama yang menjadi kelemahan adalah kecepatan dan lamanya waktu proses pengujian, dan kecermatan dalam memasukkan data uji. Kelemahan ini harus terus diperkecil dan menjadi faktor utama dalam perbaikan.

Hasil analisis, pembobotan, dan rating faktor internal disajikan dalam tabel EFAS (Tabel 2). Penilaian peluang dan ancaman perusahaan digunakan nilai 1 sampai dengan 4. Nilai 1 (ancaman utama), 2 (ancaman kecil), 3 (peluang kecil), 4 (peluang utama). Hasil pembobotan dan rating pada faktor strategi eksternal (matriks EFAS) didapatkan nilai diatas 2,5 yaitu 2,702. Hal ini berarti PT XYZ dapat memanfaatkan peluang terhadap pesaingan di industri yang sama dan lingkungan eksternal yang umum, baik masyarakat maupun pemerintah.

Peluang yang dapat dimanfaatkan berdasarkan matrik EFAS dengan nilai yang tertinggi sebesar 0,396 yaitu perusahaan pendukung atau pemasok alat teknologi pengujian dan bahan uji. PT XYZ harus mampu memelihara dan meningkatkan kerjasama dengan penyedia alat dan bahan uji dalam hal penguatan teknologi dan metodologi pengujian dengan instrumen serta kerjasama dengan penyedia rapid test. Dengan demikian kebutuhan pengujian akan ter-Up to date. Perkembangan teknik pengujian dengan cepat dikuasai oleh PT XYZ akan menjadi peluang yang sangat besar karena mampu mengujikan parameter uji yang belum mampu dilakukan oleh perusahaan jasa uji lainnya. Hal ini menjadikan PT XYZ sebagai laboratorium rujukan yang mampu memenuhi permintaan pengujian baik secara regulasi maupun perkembangan mengenai produk yang aman.

Ancaman yang dapat direspon dengan baik berdasarkan tabel EFAS yaitu harga uji jasa layanan sebesar 0,238. Harga uji ini merupakan persaingan yang sangat kompetitif pada pasar jasa layanan pengujian. PT XYZ harus berupaya memberikan harga yang bersaing dengan perusahaan jasa pengujian lainnya tanpa menurunkan kualitas pengujian dan layanan. Produk pengujian yang lengkap dari perusahaan pesaing dapat diimbangi oleh PT XYZ dengan metode uji, peralatan analisa, peningkatan kapasitas pengujian, serta layanan analisa yang unik dan inovatif yang belum dilakukan oleh pesaing.

Memilih alternatif strategi yang tepat untuk PT XYZ Penentuan posisi strategis untuk mengetahui keberadaan PT XYZ di kuadran berapa serta untuk mengetahui strategi yang sebaiknya digunakan, maka dilakukan analisis matriks IE. Penentuan strategi tersebut didapatkan dari matriks IFAS dan EFAS seperti pada Gambar 3. Hasil nilai rataan IFAS 2,785 diartikan bahwa posisi internal PT XYZ berada pada kategori kekuatan sedang (skor IFAS 2,0-3,0). Hasil evaluasi nilai rataan EFAS 2,583 diartikan bahwa kemampuan PT XYZ merespon perubahan faktor eksternal peluang dan ancaman berada pada posisi sedang (skor EFAS $2,0-3,0)$.

Berdasarkan total skor hasil evaluasi IFAS dan EFAS menempatkan posisi PT XYZ pada sel V (pertumbuhan: menjaga dan mempertahankan). Oleh karena itu, strategi yang disarankan adalah strategi intensif dengan penetrasi pasar dan pengembangan pengujian, artinya PT XYZ tetap terus melakukan strategi pemasaran yang telah dilakukan dan tetap menjaga mutu pengujian agar tetap bersaing.

Perumusan alternatif strategi dilakukan dengan analisis matrik SWOT yaitu berdasarkan analisis matriks IFAS dan EFAS sebelumnya. Berdasarkan data analisis matriks IFAS dan EFAS dapat disusun analisis matrik SWOT untuk mengidentifikasi berbagai faktor secara sistematis dalam merumuskan strategis perusahaan. Perumusan strategi PT XYZ dengan matriks SWOT dapat dilihat pada Tabel 3. 
Total Skor IFAS

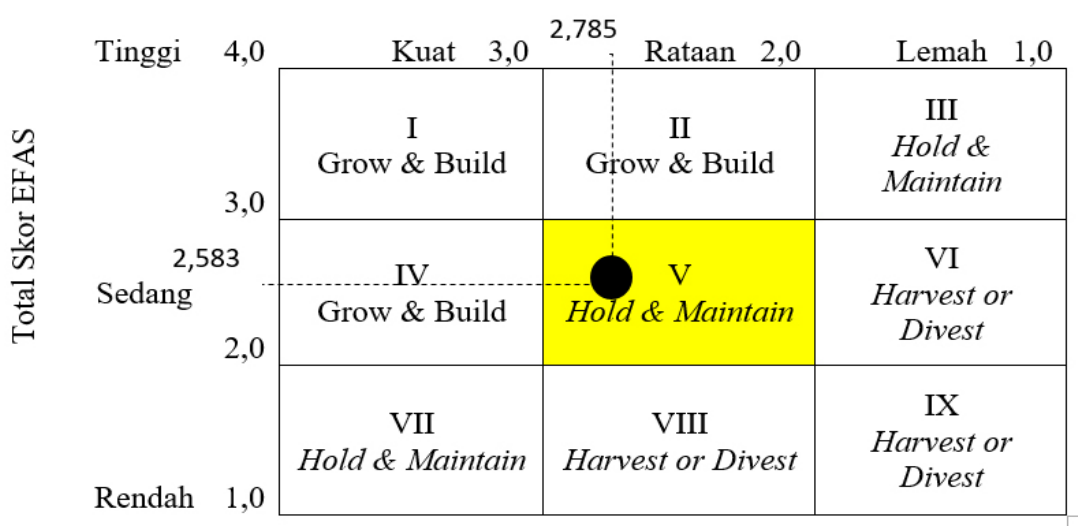

Gambar 3. Matrix IE

Tabel 3. Analisis Matrik SWOT / TOWS

\begin{tabular}{|c|c|c|}
\hline EFAS & $\begin{array}{l}\quad \text { Kekuatan/Strengths }(\mathrm{S}) \\
\text { 1. } \\
\text { 2. } \\
\text { 3. Kontrak pengujian yang mudah } \\
\text { 3. } \\
\text { Kecepatan informasi kepada } \\
\text { pelanggan } \\
\text { 4. } \\
\text { Insentif untuk karyawan dan } \\
\text { kepuasan kerja karyawan } \\
\text { 5. Aktivitas penelitian dan } \\
\text { pengembangan pengujian }\end{array}$ & $\begin{array}{l}\text { Kelemahan/Weakness }(\mathrm{W}) \\
\text { 1. Kecepatan dan lama waktu pengujian } \\
\text { 2. Kecermatan dalam preparasi sampel } \\
\text { uji dan pembuatan data uji } \\
\text { 3. Mutu layanan, pelatihan dan } \\
\text { pendidikan untuk pelanggan dalam } \\
\text { penanganan komplain } \\
\text { 4. Rasio jumlah pelatihan sesuai dengan } \\
\text { kompetensi } \\
\text { 5. Jaminan mutu metode pengujian yang } \\
\text { sulit }\end{array}$ \\
\hline $\begin{array}{l}\text { Peluang/Opportunity }(\mathrm{O}) \\
\text { 1. Pemberlakuan pengujian terhadap } \\
\text { produk (Regulasi) } \\
\text { 2. Menjadi anggota Asosiasi/Jejaring } \\
\text { laboratorium pengujian yang aktif } \\
\text { 3. Edukasi masyarakat mengenai } \\
\text { keamanan dan ketahanan pangan } \\
\text { 4. Perusahaan pendukung/pemasok alat } \\
\text { dan bahan uji } \\
\text { 5. Teknologi pengujian dan sistem } \\
\text { informasi pengujian }\end{array}$ & 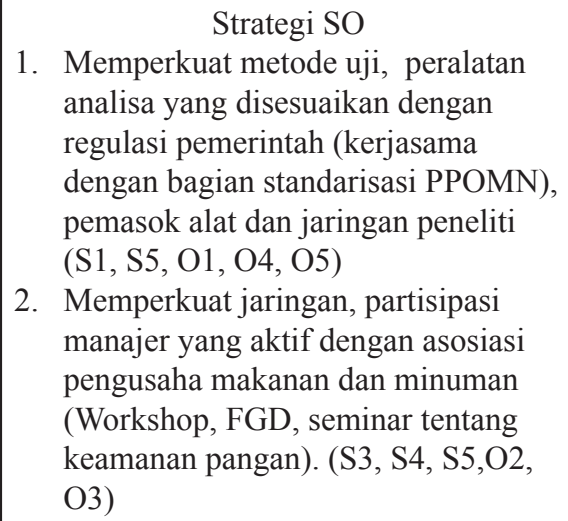 & $\begin{array}{l}\text { Strategi WO } \\
\text { 1. Meningkatkan mutu layanan } \\
\text { pengujian, baik dengan } \\
\text { meningkatkan kemampuan alat yang } \\
\text { automasi dan andal serta integrasi } \\
\text { input data dari kontrak uji sampai } \\
\text { hasil uji, memperkecil kelemahan, } \\
\text { kecepatan dan kecermatan dalam } \\
\text { data uji (valid) (W1, W2, W3, W5, } \\
\text { O4, O5) }\end{array}$ \\
\hline $\begin{array}{l}\text { Ancaman/Threaths }(\mathrm{T}) \\
\text { 1. Produk pengujian (parameter) yang } \\
\text { lengkap dari pesaing } \\
\text { 2. Harga uji jasa layanan } \\
\text { 3. Peningkatan kapasitas pengujian } \\
\text { (lama waktu uji) } \\
\text { 4. Pencemaran limbah yang dihasilkan } \\
\text { 5. Pengaruh kebijakan pemerintah } \\
\text { terhadap munculnya perusahaan baru }\end{array}$ & 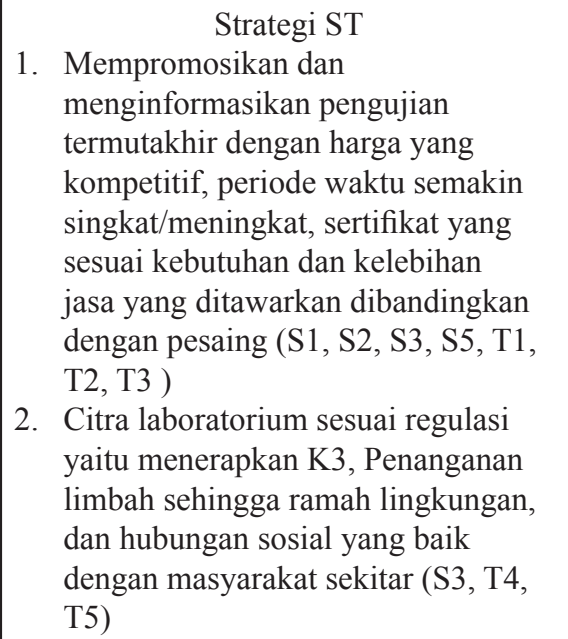 & $\begin{array}{l}\text { Strategi WT } \\
\text { 1. Meningkatkan SDM (personil di } \\
\text { tiap bagian, bagian K3, penanganan } \\
\text { limbah dan lingkungan) (W2, W3, } \\
\text { W4, T4, T5) }\end{array}$ \\
\hline
\end{tabular}


PT XYZ merupakan unit bisnis laboratorium yang berupaya untuk berkembang secara keseluruhan dengan mengalokasikan sumber daya yang dimiliki guna menciptakan sinergi mengembangkan unit bisnisnya. Strategi yang akan dijalankan atau yang dipilih adalah yang sesuai dengan unit bisnis yang ditekankan untuk meningkatkan posisi bersaing, yaitu strategi diferensiasi jasa. Diferensiasi menurut Kotler (2009) adalah tindakan merancang satu set perbedaan yang berarti untuk membedakan penawaran perusahaan dari penawaran pesaing. Hasil analisis visi, misi, posisi PT XYZ dan alternatif strategi yang dihasilkan menjadi dasar penyusunan sasaran, tujuan dan perencanaan jangka panjang PT XYZ pada Tabel 4.

Tabel 4. Tujuan, Strategi dan Program PT XYZ

\begin{tabular}{|c|c|}
\hline Sasaran dan Tujuan & Strategi dan Program \\
\hline $\begin{array}{l}\text { Penetrasi pasar dan } \\
\text { Pengembangan } \\
\text { produk (diferensiasi } \\
\text { pelayanan) }\end{array}$ & $\begin{array}{l}\text { a. Perluasan dan pengembangan metode uji berdasarkan parameter dan matrik/jenis sampel } \\
\text { - } \quad \text { Melengkapi parameter uji untuk pasar SNI, PPOMN dan uji yang diminta oleh pelanggan } \\
\text { terutama di bagian penelitian dan pengembangan } \\
\text { - Mempertahankan akreditasi dan menambah ruang lingkup pengujian } 100 \text { parameter uji } \\
\text { setiap dilakukan asesmen/reakreditasi oleh Komite Akreditasi Nasional } \\
\text { - } \quad \text { Investasi peralatan instrumen uji dan pendukungnya, sesuai dengan metode uji yang } \\
\quad \text { dikembangkan }\end{array}$ \\
\hline $\begin{array}{l}\text { Laboratorium } \\
\text { pengujian yang } \\
\text { terkemuka }\end{array}$ & $\begin{array}{l}\text { b. Menggunakan kekuatan promosi secara maksimal } \\
\text { - Pemasaran diarahkan untuk jenis uji selain pangan seperti kosmetik, farmasi dan produk } \\
\text { yang masih berkaitan dengan jenis parameter uji yang sudah ada. } \\
\text { - Penelusuran pelanggan-pelanggan tidur periode } 5 \text { tahun ke belakang } \\
\text { c. Mengurangi biaya operasional/Cost reduction } \\
\text { - Investasi sarana dan prasarana komputerisasi. } \\
\text { - Kaji ulang keefektifan metode uji dan efesiensi penggunaan instrumen uji } \\
\text { - Pengawasan penggunaan bahan kimia yang kedaluarsa dan perawatan instrumen } \\
\quad \text { pengujian }\end{array}$ \\
\hline
\end{tabular}

Pemenuhan kepuasan pelanggan

Menghasilkan data yang kredibel dan tatakelola perusahaan yang baik a. Peningkatan mutu pelayanan

- Integrasi bagian Customer Service dengan jaminan mutu pengujian sebagai satu tim

- Tanggapan komplain/keluhan pengujian selesai $<5$ hari kerja

- Mengintegrasi bagian kontrak uji dengan bagian pembayaran sebagai layanan prima

- Ekspansi wilayah yang luas (Sumatera, Kalimantan, Sulawesi) untuk pengambilan/ pengiriman sampel

b. Citra publik dan pelanggan

- Mengadakan workshop/focus group discussion mengenai pengujian terbaru dan regulasi mengenai keamanan pangan.

- Mengadakan promosi di waktu sedikit pengujian, seperti hari raya (lebaran) dan akhir tahun

- Pemberian insentif berdasarkan jumlah dan paket pengujian

c. Pemberdayaan organisasi dengan asosiasi

- Membuat perjanjian yang saling menguntungan dengan penyedia jaringan, alat dan instrumen, serta bahan pereaksi uji (teknis dan finansial)

- Pelatihan jaringan dan aplikasi komputer

a. Pengembangan kemampuan di bidang administrasi, teknologi dan kebijakan, (Strategi Pengembangan SDM)

- Melakukan penelitian dan pengembangan dengan jaringan universitas/pendidikan, konsultan dan penyedia aplikasi baik jaringan internet, alat instrrumen pengujian, dan piranti lunak sistem manajemen laboratorium

- Menyiapakan SDM untuk pengelolaan limbah dan memperkuat bidang K3 serta tanggung jawab sosial perusahaan terhadap dampak kegiatan usaha

b. Meningkatkan kinerja organisasi

- Pelatihan untuk bagian administrasi, teknis, teknologi, keuangan dan kebijakan (manajemen resiko, Six-sigma, pelaporan keuangan, pendalaman manajemen mutu)

- Investasi sarana dan prasarana komputerisasi 


\section{Implikasi Manajerial}

Pemilihan strategi berdasarkan alternatif strategi yang akan dijalankan adalah strategi bersaing dengan cakupan diferensiasi jasa yang mendukung perluasan pasar dan pengembangan produk parameter pengujian. Diferensiasi pelayanan yang harus terus ditingkatkan yaitu kemudahan dalam kontrak pengujian, pengambilan sampel dan pengiriman sertifikat uji sesuai tengat waktu pengujian, serta kemudahaan dalam hal administratif. Selain itu, mempermudah pelanggan dalam mengembangkan metode uji dan pelanggan yang membutuhkan validasi metode uji yang cepat karena keterbatasan alat dan personil analis laboratorium dari pelanggan. Keterlibatan para manajer untuk meningkatkan layanan harus terus dibangun, diantaranya adalah teknis pengujian yang didukung oleh manajer laboratorium sebagai salah satu narasumber dan dikoordinir oleh manajer pemasaran dan penjualan dengan membuat agenda-agenda atau acara yang meningkatkan customer royalty. Manajer pemasaran menjelaskan mengenai produk pengujian dan manajer laboratorium memberikan penjelasan mengenai pengujian secara ilmiah sesuai dengan kompetensinya sehingga meningkatkan pemahaman tentang pengujian kepada pelanggan.

Layanan yang memuaskan pelanggan terkait dengan permintaan uji baru dan pengujian yang belum bisa dilakukan oleh laboratorium lain dengan memperkuat metode uji yang ada. Pemenuhan peralatan uji yang sesuai dengan permintaan pelanggan terutama disesuaikan dengan persyaratan regulasi pemerintah. Selain itu, memperkuat kerja sama antara bagian penelitian dan pengembangan dengan penyedia alat laboratorium khususnya bagian aplikasi metode pengujian. PT XYZ diutamakan selalu mendapat metode uji terkini dengan menggunakan instrumen pengujian, baik dari penyedia instrumen maupun dari penyedia rapid test. PT XYZ menjadi laboratorium rujukan yang dapat memenuhi permintaan pengujian, baik secara regulasi maupun perkembangan mengenai produk yang aman.

\section{KESIMPULAN DAN SARAN}

\section{Kesimpulan}

Hasil identifikasi faktor lingkungan internal yang menjadi kekuatan dan kelemahan diantaranya adalah aktivitas penelitian dan pengembangan pengujian, insentif untuk karyawan dan kepuasan kerja karyawan, dukungan peralatan analisa, kecermatan dalam preparasi sampel uji dan pembuatan data uji, serta jaminan mutu metode pengujian yg sulit yang dapat mempengaruhi kecepatan dan lama pengujian. Di sisi lain, hasil identifikasi faktor lingkungan eksternal yang menjadi peluang dan ancaman diantaranya adalah perusahaan pendukung atau pemasok alat dan bahan uji, pemberlakuan pengujian terhadap produk (regulasi), harga uji jasa layanan, peningkatan kapasitas pengujian (lama waktu uji), dan produk pengujian (parameter) yang lengkap dari pesaing.

Analisis kekuatan dan kelemahan pada matrik IFAS menunjukkan posisi internal PT XYZ berada pada kategori kekuatan sedang. Hasil evaluasi nilai rataan EFAS diartikan bahwa kemampuan PT XYZ merespon perubahan faktor eksternal peluang dan ancaman berada pada posisi sedang. Nilai skor IFAS dan EFAS memposisikan perusahaan pada matrik IE pada sel V, yaitu strategi menjaga dan mempertahankan. Alternatif strategi yang tepat untuk PT XYZ adalah penetrasi pasar, pengembangan parameter uji untuk produk lain serta diferensiasi layanan jasa pengujian yang mampu meningkatkan citra produk dan perusahaan.

Penetapan sasaran, tujuan, strategi serta program perencanaan jangka panjang untuk PT XYZ tahun 2019-2023 telah sesuai dengan visi, misi dan analisa pengembangan strategi, yaitu sebagai laboratorium pengujian yang terkemuka serta dapat memenuhi kepuasan pelanggan. Penetapan ini dijadikan sebagai alternatif pengembangan strategi bagi industri jasa analisa untuk menghadapi perubahan di masa yang akan datang .

\section{Saran}

PT XYZ sebagai posisi pesaing bagi perusahaan yang sejenis, perang harga yang dilakukan oleh perusahaan lain harus dihindari dengan melakukan promosi tentang mutu layanan berupa kecepatan uji, akurat dan bisa diterima oleh regulator. Kecenderungan dari strategi diferensiasi, yaitu menurunkan biaya pengujian. Selain itu, penelitian harus lebih diarahkan kepada bagian marketing. Sedangkan untuk meningkatkan kecepatan pengolahan data diperlukan sistem manajemen informasi laboratorium sehingga harus dilakukan penelitian tentang persiapan, pembentukan dan pengelolaan data berbasis jaringan. 


\section{DAFTAR PUSTAKA}

Abdurrahim MFH, Arief D, Rita N. 2014. Strategi pengembangan balai penelitian bioteknologi perkebunan indonesia. Jurnal Manajemen \& Agribisnis 11(3): 199-208.

Azzuhro M. 2015. Perencanaan strategik bisnis baru jasa salon dan spa studi kasus CV. XYZ [tesis]. Bogor: Sekolah Program Pascasarjana, Institut Pertanian Bogor $=$.

David FR. 2013. Strategic Management, concept and case. 14th ed. New Jersey: Prince Hall. Upper Sadle River.

Dewi NR, Sukardi, Setiadi Djohar. 2018. Formulasi strategi pengembangan bisnis salon XYZ. Jurnal Aplikasi Bisnis dan Manajemen 4(3): 365-375. https://doi.org/10.17358/JABM.4.3.365.

Dila P, Arif IS, Mukhamad N. 2014. Analisis strategi peningkatan daya saing sayuran organik. Jurnal Manajemen dan Organisasi 5(3): 258-270. https://doi.org/10.29244/jmo.v5i3.12177.

Hasnam LF, Rizal S, Ahmad MY. 2017. Strategi pengembangan bank sampah di wilayah Depok. Jurnal Aplikasi Bisnis dan Manajemen 3(3). http://dx.doi.org/10.17358/jabm.3.3.407.

Hutabarat J, Martani H. 2006. Pengantar Manajemen Strategik Kontempoler Strategik di Tengah Operasional. Jakarta: Gramedia

Kamila R, Rizal S, Imam TS. 2017. Analisis pengembangan bisnis madu pada CV Ath-Thoifah dengan pendekatan business model canvas. Jurnal Agribisnis Indonesia 5 (2): 173-184. https://doi. org/10.29244/jai.2017.5.2.173-184.

Kaoje AU, Umar M, Yahaya M. 2017. Quality of medical laboratory services in a tertiary health institution in Sokoto, Nigeria. International Journal of Medical Laboratory 4(4): 246-259.

Kotler P, Keller KL. 2009. Manajemen Pemasaran. edisi 13th. Jilid 1. Jakarta: Penerbit Erlangga.

Munandar. 2011. Analisis strategi pemasaran jasa laboratorium pangan (studi kasus pada M-brio Food Laboratory). Jurnal Manajemen dan Organisasi II(3):67-78. http://journal.ipb.ac.id/ index.php/jmo/article/view/14209/10589

Nugroho AW. 2017 Strategi Bisnis PT Pelayaran Bahtera Adhiguna dalam Industri Pelayaran. (tesis). Bogor: Institut Pertanian Bogor.

Nurhasanah N. 2013. Startegi Pengembangan Laboratorium Program Studi Teknik Industri di Universitas Al Azhar Indonesia. Jurnal Al-Azhar Indonesia Seri Sains dan Teknologi 2(1): 11-25. https://doi.org/10.36722/sst.v2i1.92.

Pearce II, J.A, Robinson Jr, R.B. 2014. Strategic Management-Formulation, Implementasion and Control. (Terjemahan). Jakarta: Salemba Empat.

[PPPOMN] Pusat Pengembangan Pengujian Obat dan Makanan. Laporan Tahunan PPOMN. https:// www.pom.go.id/pppomn/pages/lap_tahunan. [10 Juli 2018].

Purwani, Lukman MB, imam TS. 2019. Formulasi strategi bisnis Perusahaan Original Equipment Manufacturer (OEM). Jurnal Aplikasi Bisnis dan Manajemen 3(2): 172-184. https://doi.org/ 10.17358/JABM.5.1.13.

Putra IKPS, Rizal S, Sahara. 2017. The business model analysis of wika lab using business canvas approach. European Journal of Business and Management 9(2):56-66.

Rachman IS, Aida VSH, Suryani SMF. 2017. Strategi peningkatan brand loyalty dan customer satsfaction bisnis yogurt di Indonesia. Jurnal Aplikasi Bisnis dan Manajemen 3(2):324-333. https://doi.org/10.17358/JABM.3.2.324

Singh H, Jeffry JM, Nur NAM, Soon Sigh. 2018. The impact of service quality deliveri toward customer satisfactionin medical diagnostics laboratory industry. The Turkish Online Journal of Design, Art and Communication - TOJDAC. Special Edition: 3054-3064. https://doi. org/10.7456/1080SSE/382.

Suprapto, Baga LM, Kirbrandoko. 2017. Perencanaan Strategi SBU Mineral PT Sucofindo (Persero). Jurnal Aplikasi Bisnis dan Manajemen 3(2): 172184. https://doi.org/10.17358/JABM.3.2.172.

Suryani, D. Rizal S. Arif IS. 2014. Perancangan balanced scorecard untuk pengembangan strategi di Seameo Biotrop. Jurnal Manajemen \& Agribisnis 11 (1):33-40.

Wheelen TL, Hunger JD. 2012. Strategic management and busness policy. 13thed. Amaerican: Person Education, Inc. Upper Saddler River.

Wieklati. 1998.Analis strategi pemasaran jasa pelayanan Balai Laboratorium Kesehatan Yogyakarta. Jurnal Manajemen Pelayanan Kesehatan 1(01): 19-24

Widyastutik, Reni KA. 2014. Analisis strategi kebijakan mutu dan standar produk kayu lapis dalam rangka meningkatkan daya saing ekspor. Jurnal Agribisnis Indonesia 2(1): 75-92. https://doi. org/10.29244/jai.2014.2.1.75-92. 